\title{
Editorial
}

\section{China e África além da economia: qual o impacto do FOCAC na arena multilateral (1971-2014)?}

China and africa beyond economy: what is the impact of FOCAC in the multilateral arena (1971-2014)?

DOI: 10.5752/P.1809-6182.2016v13.n3.p153

Renan Holanda Montenegro ${ }^{1}$

João Ricardo Cumarú Silva Alves

RESUMO

Recebido em: 26 de junho de 2016 Aprovado em: 15 de setembro de 2016

Este trabalho avalia se houve aumento da afinidade sino-africana após a criação do FOCAC. Para tanto, utilizamos dados de votaçóes da Assembleia Geral da ONU para comparar o nivel de afinidade das diades envolvendo China e os integrantes do Fórum antes e depois de sua criação, em 2000.

Palavras-chave: China-Africa. FOCAC. AGNU.

\section{ABSTRACT}

This work evaluates whether there was an increase of Sino-African affinity after the foundation of FOCAC. Therefore, we use the UN General Assembly voting data to compare the level of affinity of dyads involving China and the members of the Forum before and after its creation, in 2000.

Keywords: China-Africa. FOCAC. UNGA.

1. Mestre em Relaçôes Internacionais (UERJ) e doutorando em Ciência Política (UFPE). Pesquisador Associado do Instituto de Estudos da Ásia (UFPE). orcid.org/0000-0002-4371-5466

2. Bacharel em Ciência Política pela Universidade Federal de Pernambuco (UFPE). Membro do Núcleo de Estudos e Pesquisas Regionais e de Desenvolvimento (D\&R) e colaborador do Instituto de Estudos da Ásia (UFPE). orcid.org/0000-0003-3610-3127 


\section{Introdução}

O início das relações entre a China e o continente africano data ainda do século 15, época das navegaçôes comandadas pelo almirante Zheng He, um muçulmano eunuco enviado pela Dinastia Ming para realizar viagens de exploração. Mitchell e McGiggert (2007) afirmam que aquele momento representava o auge do poder global chinês. Contemporaneamente, as relaçóes sino-africanas passaram a ter status de prioridade dentro da agenda da política externa chinesa. O estabelecimento da República Popular da China (RPC), em 1949, representou um marco na aproximação entre as partes, mesmo que num contexto extremamente influenciado pela Guerra Fria.

O episódio da aceitação da China comunista no lugar da rival nacionalista na Organização das Nações Unidas (ONU), em 1971, já dava sinais da alta convergência sino-africana no âmbito multilateral: mais de $1 / 3$ dos votos recebidos pela China vieram de países africanos. A institucionalização da parceria, com a criação do Forum on China-Africa Cooperation (FOCAC) em 2000, foi decisiva para um fortalecimento ainda maior desses laços. Os ganhos no âmbito financeiro e comercial são notáveis: naçōes africanas receberam vultosos investimentos chineses e a China, em troca, abriu caminho para suprir sua demanda por recursos energéticos. Entretanto, o FOCAC conseguiu aumentar a convergência de interesses entre seus membros no âmbito multilateral?

O objetivo deste trabalho é investigar como se comportou a afinidade entre China e os países africanos membros do FOCAC antes e após a institucionalização do Fórum. Para tanto, replicamos os dados do banco de Voeten (2013) para investigar o grau de convergência de interesses entre China e África nas votaçốes da Assembleia Geral das Naçôes Unidas (AGNU).
Além desta introdução, o texto está dividido em outras cinco partes:

- apresentação de breve histórico das relaçóes sino-africanas pós-1949;

- descrição sobre a evolução do FOCAC;

- apresentação da metodologia;

- discussão dos resultados; e

- comentários conclusivos. Com isso, esperamos prestar uma contribuiçáo para a literatura sobre política externa chinesa em geral e as relações sino-africanas em particular, lançando luz em elementos que vão além da dinâmica meramente econômica.

\section{Relações sino-africanas pós-1949: um breve histórico}

A partir da constituição da RPC com a revolução de 1949, a política externa chinesa passou um período sendo associada e determinada pelas lideranças do partido, entre eles Mao Tsé-Tung, Zhou Enlai e Deng Xiaoping. Em determinados períodos, a ideologia foi um fator mais determinante do que a própria personalidade dos líderes, como, por exemplo, a época da dissensão sino-soviética (MENDES, 2008) e da Revolução Cultural (1966-1976). Entretanto, o contexto geopolítico mundial a partir das décadas de 1980 e 1990 veio a modificar as diretrizes da política externa chinesa, tornando-a menos ideológica e personalizada, e mais institucionalizada e pragmática, como descreveremos mais abaixo.

O período pós-revolucionário, comumente descrito na literatura como "confrontação com o Ocidente", fez com que a China iniciasse um processo de transição da condição de um império estático para um país economicamente dinâmico e buscasse uma readaptação da sua postura perante a comunidade internacional. Nesse momento (década de 1950), a China aproximou-se dos africanos 
através da demonstração da solidariedade anticolonialista e anti-imperialista expressas na Conferência de Bandung (1955), e passou a apoiar as lutas políticas pela independência africana, bem como forneceu ajuda para a África, para atrair os novos países ao seu campo de influência e difundir os ideais comunistas (MENEZES, 2013).

Na década de 1960, a China deu continuidade ao estreitamento das suas relaçóes com a África. Nesse sentido, houve uma nova abordagem para a referida aproximação com os países do continente africano, baseada nos princípios estabelecidos entre os anos 1963 e 1964, quando da visita do premier Zhou Enlai à África ${ }^{3}$. A partir desse momento, a China passou a apoiar o processo de independência africano. Esses princípios de ajuda foram pensados para competir simultaneamente com o bloco imperialista (Estados Unidos) e os chamados revisionistas (Uniāo Soviética), além de obter reconhecimento da diplomacia africana e o estabelecimento de novas relaçôes oficiais que reforçassem a legitimidade do regime comunista chinês.

Durante a Revolução Cultural, a China forneceu grande volume de ajuda aos países do continente, através de parcerias e investimentos na área de infraestrutura, por exemplo, com a construção de hospitais, estádios, aeroportos; açóes que representavam não somente meras construçóes, mas "símbolos nacionais de independência e incorporados pelo espírito de descolonização cultural" (ANSHAN, 2007). Um exemplo desses investimentos foi a ferrovia Tanzânia-Zâmbia (TAZARA), construída entre 1970 e 1975 . Como se vê no quadro abaixo, foi durante o período da Revolução Cultural que 20 países africanos estabeleceram relaçóes diplomáticas com a China.

3. Os Cinco Princípios são: 1) respeito mútuo acerca da soberania e integridade territorial; 2) não agressão mútua; 3) não interferência nos assuntos internos; 4) igualdade ou benefício mútuo; e 5) coexistência pacífica.
Quadro 1 - Estabelecimento de relações diplomáticars com a China (por ano)

\begin{tabular}{|c|c|}
\hline Intervalo & Países \\
\hline $\begin{array}{c}\text { Anos } \\
1950\end{array}$ & $\begin{array}{c}\text { Egito (1956), Marrocos e Argélia (1958), } \\
\text { Guiné e Sudão (1959) }\end{array}$ \\
\hline $\begin{array}{c}\text { Anos } \\
1960\end{array}$ & $\begin{array}{c}\text { Somália (1960), Uganda (1962), Quênia } \\
\text { (1963), Congo, Tanzânia, Tunísia, e Zâmbia } \\
\text { (1964), Mauritânia (1965) }\end{array}$ \\
\hline $\begin{array}{c}\text { Anos } \\
1970\end{array}$ & $\begin{array}{c}\text { Burunia, Guiné Equatorial e Mali (1970), Camaróes, Nigéria, Ruanda e Ser- } \\
\text { ra Leoa (1971), Benin, Gana, Madagascar, } \\
\text { Maurício, R. D. do Congo e Togo (1972), } \\
\text { Gabão (1974), Botsuana, Comores e Moçam- } \\
\text { bique (1975), Cabo Verde e Seychelles (1976), } \\
\text { Líbia (1978), Djibuti (1979) }\end{array}$ \\
\hline $\begin{array}{c}\text { Anos } \\
1980\end{array}$ & $\begin{array}{c}\text { Zimbábue (1980), Angola e Costa do Marfim } \\
\text { (1983) }\end{array}$ \\
\hline $\begin{array}{c}\text { Anos } \\
1990\end{array}$ & $\begin{array}{c}\text { Namíbia (1990), Eritreia (1993), Lesoto } \\
\text { (1994), Níger (1996), Guiné-Bissau, Repúbli- } \\
\text { ca Centro-Africana e África do Sul (1998) }\end{array}$ \\
\hline $\begin{array}{c}\text { Libéria (2003), Senegal (2005), Chade } \\
2000\end{array}$ & $\begin{array}{c}\text { (2006), Malaui (2007), Sudão do Sul (2011) } \\
\text { Anos }\end{array}$ \\
\hline
\end{tabular}

Fonte: Elaborado pelos autores com dados extraídos de de FOCAC (2016)

Fica nítido que os anos 1970 foram essenciais para o estreitamento dos laços sino-africanos, já que este período registrou o maior número de relações diplomáticas entre as partes. Em particular, os anos de 1972 (seis relaçóes estabelecidas) e 1971 (cinco) são, respectivamente, o $1^{\circ} \mathrm{e} \mathrm{o} 2^{\circ}$ momentos em que foram estabelecidas a maior quantidade de relaçôes diplomáticas. O ano de 1964, com quatro reconhecimentos, ocupa a $3^{\mathrm{a}}$ posiçáo. Através do Gráfico $1^{4}$, também se pode notar que houve uma espécie de estagnação neste cenário a partir da metade dos anos 1970. Dali em diante, os países que ainda não haviam estabelecido relaçôes oficiais com a China comunista passaram a fazê-lo a conta-gotas - exceto os anos de 1983 e 1998, quando houve, respectivamente, dois e três reconhecimentos diplomáticos.

4. Não incluímos os anos em que nenhum país estabeleceu relaçôes diplomáticas com a China, já que estamos interessados na variação das variáveis aqui trabalhadas: ano e quantidade de países, ambas variáveis quantitativas discretas. 
Gráfico 1. Quantidade de países que estabeleceram relações diplomáticas com a China (por ano)

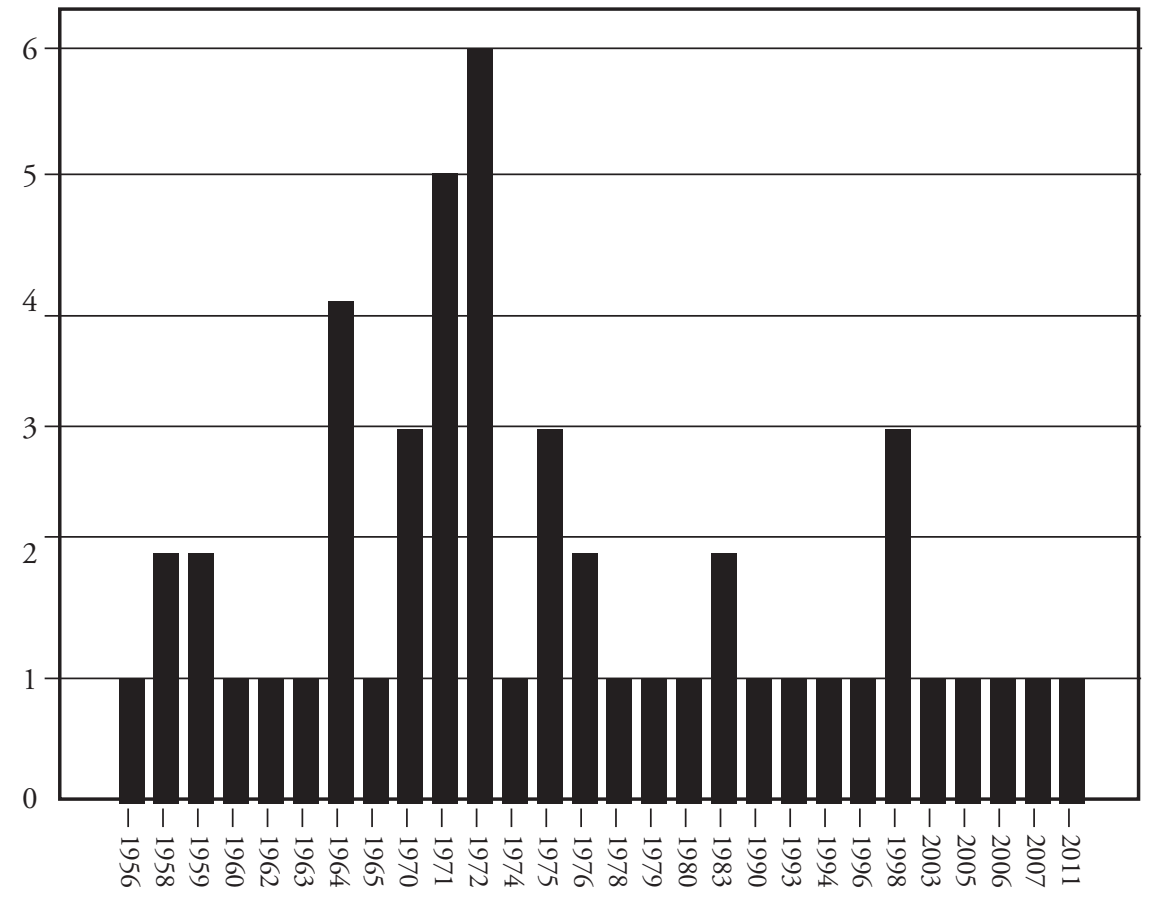

Fonte: Elaborado pelos autores com dados extraídos de de FOCAC (2016)

O período de abertura econômica do final da década de 1970 foi caracterizado por uma transição do caráter ideológico para uma aproximação de cunho mais pragmático e diversificado com a África. O novo foco no desenvolvimento interno de sua economia levou a um ajuste gradual da política externa chinesa para o continente africano, agora focada em estabelecer uma cooperação econômica mutuamente benéfica e a promoção de contratos de serviços, investimentos e comércio (ANSHAN, 2007; SUN, 2014).

Na década de 1980, a atuação internacional da China consolidou o que o governo havia começado anos antes e o discurso ideológico leste-oeste cedeu espaço a um viés mais liberal ensejado pela própria abertura de Xiaoping; tanto que o país ingressou no Banco Mundial e no Fundo Monetário Internacional. Esses anos foram caracterizados por um retrocesso na cooperação sino-africana, já que os chineses teriam perdido interesse pelo continente, pois acreditavam não precisar de apoio externo ao seu projeto de crescimento e desenvolvimento econômico.
Somente três países africanos estabeleceram relaçōes diplomáticas com a China nesse período.

Contudo, os laços sino-africanos vieram a sofrer mais uma reviravolta, tomando um novo rumo após a repercussão negativa do "Massacre de Tianamen" no Ocidente. A partir de entáo, e somando isso ao fim da autossuficiência chinesa em petróleo, as relaçóes sino-africanas cresceram significativamente ao longo da década de 1990. A estratégia chinesa passou a ser mais aguda: visava garantir recursos naturais, mercados consumidores e a posição de líder no mundo em desenvolvimento.

\section{O FOCAC e a institucionalização da parceria}

O lançamento do FOCAC, em 2000, marcou o início do processo de fortalecimento e institucionalização das relaçôes sino-africanas. Reunindo quase todos os países do continente, o Fórum tornou-se a principal plataforma de diálogo e coordenação 
China-África a partir de um discurso marcado pela construção de uma identidade comum, além de recuperar e reafirmar os Cinco Princípios de Coexistência Pacífica. Seguindo o espírito de Bandung, esses princípios passaram a ser compreendidos também como fatores de desenvolvimento, guiando o comportamento da China ao lidar com os países do mundo emergente. Por exemplo, a China comprometeu-se a respeitar o direito de cada país africano a dirigir sua política econômica de forma independente, incentivando a participação desses países na competição internacional.

O FOCAC foi lançado durante a presidência de Jiang Zemin em 2000 e, em 12 anos de existência, seu papel e influência tornaram-se cada vez mais sofisticados e abrangentes. A ideia do Fórum teve origem ainda no final dos anos 1990, quando países como Etiópia, Maurício e Madagascar tentaram formar um grupo para trocas comerciais com a China. A primeira Conferência Ministerial aconteceu em Pequim, com o lançamento oficial do Fórum (GRIMM, 2012). Desde então, foram seis encontros do tipo - previstos para ocorrer trienalmente. Essa primeira iniciativa contou com a participação de mais de 80 ministros da China e de 44 países africanos, representantes de organizaçôes regionais e internacionais e empresários.

O objetivo inicial do primeiro encontro era a construção de um caminho para o desenvolvimento de uma nova parceria de longo prazo marcada pela igualdade e benefícios mútuos entre a China e os países do continente africano (FOCAC, 2000a). Os questionamentos iniciais apontavam para como deveria se dar, a partir daquele momento, o relacionamento China-África e de que maneira a cooperaçáo econômica poderia ser reforçada (FOCAC, 2000b). Diversos acordos relativos a investimentos e ao comércio foram fechados, como por exemplo: a criação de fundos especiais para joint ventures; continuidade no fornecimento de assistência; perdão de dívidas que somaram 10 bilhóes de yuans.
Talvez o único enfoque diplomático abordado na primeira conferência do FOCAC tenha sido a defesa pela reforma do Conselho de Segurança da ONU. A declaração reivindicava "o reconhecimento do lugar legítimo devido à África no Conselho de Segurança e nas organizaçôes e agências especializadas do sistema das Nações Unidas" (FOCAC, 2009b). A ONU é chamada também a assumir um papel maior na resoluçâo dos conflitos que afetavam o continente à época.

Em dezembro de 2003 ocorreu a Segunda Conferência Ministerial, em Adis Abeba, Etiópia. O premier chinês Wen Jiabao, junto aos representantes africanos, propôs uma maior democratização das relaçôes internacionais por meio de consultas intensificadas e uma cooperação conjunta entre os países para superar os desafios da globalização (FOCAC, 2003; 2004a). A partir dessa reunião, cada encontro passou a emitir um Plano de Ação, que estabeleceria a orientação no avanço das relaçóes sino-africanas para os próximos três anos. Da Segunda Conferência resultou o Plano de Açáo de Adis Abeba (2004-2006), o qual reforçava as principais áreas de cooperação política e econômica já estabelecidas na declaração anterior. Destaque para o cancelamento de dívidas de 31 países africanos, somando um montante de US\$ 1,27 bilhão (FOCAC, 2004b, 2003d). Diplomaticamente, a China voltou a afirmar sua posição e compromisso de que, como membro permanente do Conselho de Segurança da ONU, estaria sempre ao lado dos países africanos não só nas Nações Unidas, como também em outras organizaçóes internacionais (FOCAC, 2009a).

A III Conferência, em 2006, ocorreu em um momento em que as relaçóes sino-africanas ganharam enorme visibilidade internacional. Esse ano foi definido como o "Ano da África" pelo governo chinês, marcando os 50 anos do estabelecimento das primeiras relaçóes diplomáticas com um país do continente: o Egito, em 1956. Em janeiro de 2006, 
foi lançado o China's Policy to Africa, documento que especifica a estratégia de longo prazo da China para o continente africano. Além disso, nesse mesmo ano, dez países do continente receberam visitas oficiais do presidente Hu Jintao e do premier Wen Jiabao (MENEZES, 2013).

$\mathrm{Na}$ ocasiāo, foi lançado o Plano de Ação de Pequim (2007-2009), no qual a China traçava um planejamento para o aprofundamento de suas relaçóes com o continente africano, principalmente no campo político-econômico. Entre as ações estabelecidas, foi colocada como meta que o comércio bilateral alcançasse os US\$ 100 bilhóes até 2010; a concessão de empréstimo de US\$ 3 bilhóes e créditos preferenciais em torno de US\$ 2 bilhôes aos países africanos; criação do Fundo de Desenvolvimento Sino-Africano com subsídio de US\$ 5 bilhôes para encorajar firmas chinesas a investir na África; construção de nova sede da Uniāo Africana; cancelamento de dívidas relacionadas a empréstimos aos países pobres altamente endividados; entre outras iniciativas (FOCAC, 2006; GRIMM, 2012).

Em 2009, reunidos em Sharm El Sheikh, Marrocos, chefes de Estado da África e China participaram da IV Conferência do FOCAC. Influenciado pelos reflexos da crise financeira internacional, o encontro foi uma tentativa de apaziguar os efeitos da crise nos países em desenvolvimento. Em linhas gerais, o Plano de Sharm El Sheikh (2010-2012) indica em maiores detalhes algumas das principais iniciativas que seriam tomadas no âmbito do FOCAC: elevação em US\$ 3 bilhóes no Fundo de Desenvolvimento sino-africano para apoio à expansão de negócios chineses na África; oferta de US\$ 10 bilhóes em empréstimos preferenciais para o desenvolvimento de projetos em infraestrutura; expansão de isenção tarifária para 95\% das exportaçôes provenientes dos países menos desenvolvidos da África (FOCAC, 2009a).
A V Reuniāo Ministerial do FOCAC reuniu, além de representantes chineses e africanos, o presidente da Comissão da União Africana. Essa foi a primeira vez que o Sudáo do Sul, criado em 2011, e a Comissão participaram como membros oficiais do Fórum (LOPES; NASCIMENTO; VADELL, 2013). O encontro foi pautado na revisão do desenvolvimento das relaçôes China-África e visava, ainda, avaliar a implementaçẫo das açôes da Conferência anterior (FOCAC, 2012a).

Além da expansão dos fundos de investimentos sino-africanos, com o Plano de Beijing 20132015, o governo da RPC deu continuidade à sua política de apoio ao desenvolvimento de zonas de cooperação econômico-comerciais tanto na China quanto na África, ademais de facilitar e ajudar a entrada de empresas chinesas e africanas nessas zonas, visando a aceleração da industrialização e reestruturação econômica da África (FOCAC, 2012b).

O encontro mais recente ocorreu em 2015, em Joanesburgo, África do Sul, fortemente influenciado pelos rumores de desaceleração da economia chinesa. Alguns economistas (MEDEIROS, 2010; RODRIK, 2011) apontam para uma transição do crescimento chinês para um ritmo mais lento e sustentável, além da flexibilização na determinação da taxa de câmbio do yuan, na tentativa de torná-lo mais confiável como moeda de reserva internacional. Os reflexos dessa mudança no perfil do modelo econômico chinês associado ao colapso no preço das commodities, além de outros fatores da crise econômica, levaram a um resfriamento das relaçóes comerciais com os africanos. Foi nesse contexto que ocorreu a VI Conferência do FOCAC.

Durante o encontro, o presidente chinês $\mathrm{Xi}$ Jinping propôs planos para impulsionar a cooperaçáo e sinalizar à comunidade internacional que a cooperaçấo sino-africana não havia perdido forças. Nesse intuito, na Declaração de Joanesburgo (FOCAC, 2015a) e no Plano de Ação 2016-2018 (FOCAC, 
2015b) foi apresentado um pacote de apoio financeiro de US\$ 60 bilhóes divididos em empréstimos preferenciais e linhas de crédito para a exportação; subsídios; capital para o CAD Fund; e empréstimos voltados ao desenvolvimento de pequenas e médias empresas africanas (FOCAC, 2015b). Ao final, a Cúpula deixou claro que, apesar das transformaçóes na economia da China e demais adversidades, os investimentos na África não foram reduzidos.

\section{Metodologia}

Para os objetivos da pesquisa, um teste de comparação de médias oferece a resposta para o nosso principal questionamento: houve aumento na afinidade entre China e África no âmbito multilateral após a criação do FOCAC? Sendo assim, foi aplicado um teste-t para amostras independentes em um banco de dados com votaçóes da Assembleia Geral da ONU (AGNU). A amostra recebeu um corte em duas:

- votações de 1971 a 1999; e

- votaçôes de 2000 a 2014. O intervalo escolhido (1971-2014) se deu por dois motivos:

a China só entra oficialmente para a $\mathrm{ONU}$ em 1971, antes disso era a China Nacionalista que ocupava o assento; os dados utilizados para os efeitos dessa pesquisa só compreendem votaçốes até $2014^{5}$.

O banco United Nations General Assembly Voting Data, de Voeten (2013), foi a base de referência para o nosso estudo. $\mathrm{O}$ banco possui quatro conjuntos de dados, sendo que o escolhido reúne dados de afinidade a partir da análise de pares entre países (díades). A afinidade entre dois países é calculada por meio de um índice que varia de -1 a 1 , onde -1 representa a menor similaridade de interesse e 1, a maior. Esse indicador é criado a partir

5. O banco de Voeten (2013), contudo, reúne dados sobre as votaçóes na AGNU desde a primeira assembleia, em 1946. de uma divisão das votaçôes em três categorias de dados: 1 = sim, para aprovação de alguma resolução; 2 = abstenção; e 3 = não, representando um voto contrário. Invariavelmente, os dados não são uniformes para todos os países, haja vista que nem todos os Estados entram oficialmente para a ONU ao mesmo tempo. Entretanto, como estamos trabalhando com uma ferramenta estatística que compara médias, essa questão não interfere nos resultados (PALLANT, 2007).

Uma exigência do teste-t para amostras emparelhadas é que os grupos analisados sejam exatamente idênticos antes e depois. Em nosso caso, comparamos um índice de afinidade (variável dependente) em duas amostras com quantidades distintas de observaçóes: no período 1971-1999 temos $\mathrm{n}=1.292$; para 2000-2014, $\mathrm{n}=725$. Isso acontece porque o intervalo de tempo que compreende o primeiro grupo é maior que o segundo, o que resulta na maior quantidade de díades. Por isso, em vez de um teste para amostras emparelhadas, aplicamos um teste-t para amostras independentes realizando um corte no ano 2000.

O principal objetivo desta análise empírica é testar a hipótese de que houve um aumento na afinidade média entre os membros do FOCAC após a institucionalização do bloco. As hipóteses nula e alternativa estão formalmente descritas abaixo.

$$
\begin{aligned}
& \mathrm{H}_{\mathrm{o}}: \overline{\mathrm{X}}_{\mathrm{A}}=\overline{\mathrm{X}}_{\mathrm{D}} \\
& \mathrm{H}_{\mathrm{a}}: \overline{\mathrm{X}}_{\mathrm{A}} \neq \overline{\mathrm{X}}_{\mathrm{D}}
\end{aligned}
$$

A hipótese nula informa que as médias de afinidade das díades com membros do FOCAC (tendo a China como unidade de referência) antes (1971-1999) e depois (2000-2014) da sua criação são iguais. Por sua vez, a hipótese alternativa informa que há diferença significativa nas afinidades antes e depois, o que corrobora a tese de que houve aumento no nível de coesão diplomática entre os 
membros do FOCAC. Na seção seguinte, apresentamos os resultados encontrados.

\section{Resultados}

As estatísticas descritivas apontam que houve uma discreta evolução na afinidade entre China e os membros africanos do FOCAC. No período anterior à criação do Fórum (1971-1999), o indicador de afinidade apresentou uma média de 0,827 ( $\mathrm{n}=1.292$ díades), enquanto o intervalo 2000-2014 registrou uma média de 0,848 ( $\mathrm{n}=725)$. A análise dos desvios-padrão, contudo, informa que houve maior homogeneidade no comportamento dos países antes da criação do bloco. Os resultados das estatísticas descritivas estão resumidos abaixo.

Tabela 1 - Estatísticas descritivas da variável "afinidade" antes e depois do FOCAC

\begin{tabular}{c|c|c|c|c|c}
\hline & $\mathrm{N}$ & Mínimo & Máximo & Média & Desvio-padrão \\
\hline $\begin{array}{c}1971- \\
1999\end{array}$ & 1292 & -1 & 1 & 0,827 & 0,085 \\
\hline $\begin{array}{c}2000- \\
2014\end{array}$ & 725 & 0,333 & 1 & 0,848 & 0,131 \\
\hline
\end{tabular}

Fonte: Elaborado pelos autores.

Apesar da discreta evolução da afinidade média na comparação dos dois períodos, os resultados do teste-t indicam que a diferença é estatisticamente significativa $(t=4,363 ; p>0,001)$. Por meio dos dados obtidos com o Teste de Levene para igualdade de variâncias $(\mathrm{F}=15,916 ; \mathrm{p}<0,001)$, pode-se rejeitar a hipótese nula e aceitar a hipótese alternativa, qual seja: a de que houve um aumento na afinidade entre os países-membros do FOCAC após a criação do bloco.

\section{Tabela 2 - Teste-t para igualdade de médias}

\begin{tabular}{c|c|c|cc}
\hline $\begin{array}{c}\text { Sig (2 ex- } \\
\text { tremidades) }\end{array}$ & $\begin{array}{c}\text { Diferença } \\
\text { média }\end{array}$ & $\begin{array}{c}\text { Erro padrão } \\
\text { da diferença }\end{array}$ & $\begin{array}{c}95 \% \text { intervalo de } \\
\text { confiança da diferença }\end{array}$ \\
\hline 0,000 & 0,021 & 0,005 & $\begin{array}{c}0,116 \\
0,305 \\
\text { (inferior) }\end{array}$ & \begin{tabular}{c} 
(superior) \\
\hline
\end{tabular} \\
\hline
\end{tabular}

Fonte: Elaborado pelos autores.
Apesar de a média maior pertencer ao grupo de díades a partir de 2000, a maior afinidade média de toda a série $(0,912)$ foi observada em 1989 , no intervalo anterior à criação do bloco. Em 1990 e 1991, a média foi de 0,909. Curiosamente, grande parte das maiores afinidades médias aconteceram antes da criação do bloco: 0,901 em 1979; 0,895 em 1981; 0,893 em 1980; 0,892 em 1988. Acontece que as menores médias também foram registradas antes da criação do bloco, sendo a menor delas observada em $1971(0,580)$, exatamente o ano em que a China entra oficialmente para as Naçóes Unidas. Durante os anos 1970, a afinidade média permaneceu basicamente na casa dos 0,7 . O gráfico abaixo ilustra bem a variação da afinidade média ao longo dos anos.

Como se vê, o período anterior à criação do FOCAC possui alguns picos de afinidade, como em 1979 (0,901), que registrou a maior média entre 1971 e 1988. Em 1989, há o maior resultado da série que compreende o intervalo 1971-1999 - e de toda a série: 0,912. Após 1989, a afinidade entre China e África só registrou quedas, voltando a crescer de forma significativa a partir de 2000, exatamente o ano da criação do Fórum. De 1999 para 2000, a afinidade média passou de 0,780 para 0,854. O pico do intervalo 2000-2014 acontece em 2002, quando a média atinge 0,902 , único resultado acima de 0,9 para todo o período em questáo.

\section{Consideraçóes finais}

Apesar da significância estatística do aumento da afinidade sino-africana após a criação do FO$\mathrm{CAC}$, não se pode dizer que tal resultado aconteceu por causa do Fórum. Testes extras são necessários para realizar inferências causais e testar hipóteses nesse sentido. Um esforço de pesquisa nessa linha foi feito por Flores-Macias e Kreps (2013), que coletaram ampla quantidade de dados para avaliar o impacto das relaçóes comerciais na afinidade diplomática no âmbito da AGNU. Os resultados 
Grófico 2. Evolução da afinidade média entre os membros do FOCAC (1971-2014)

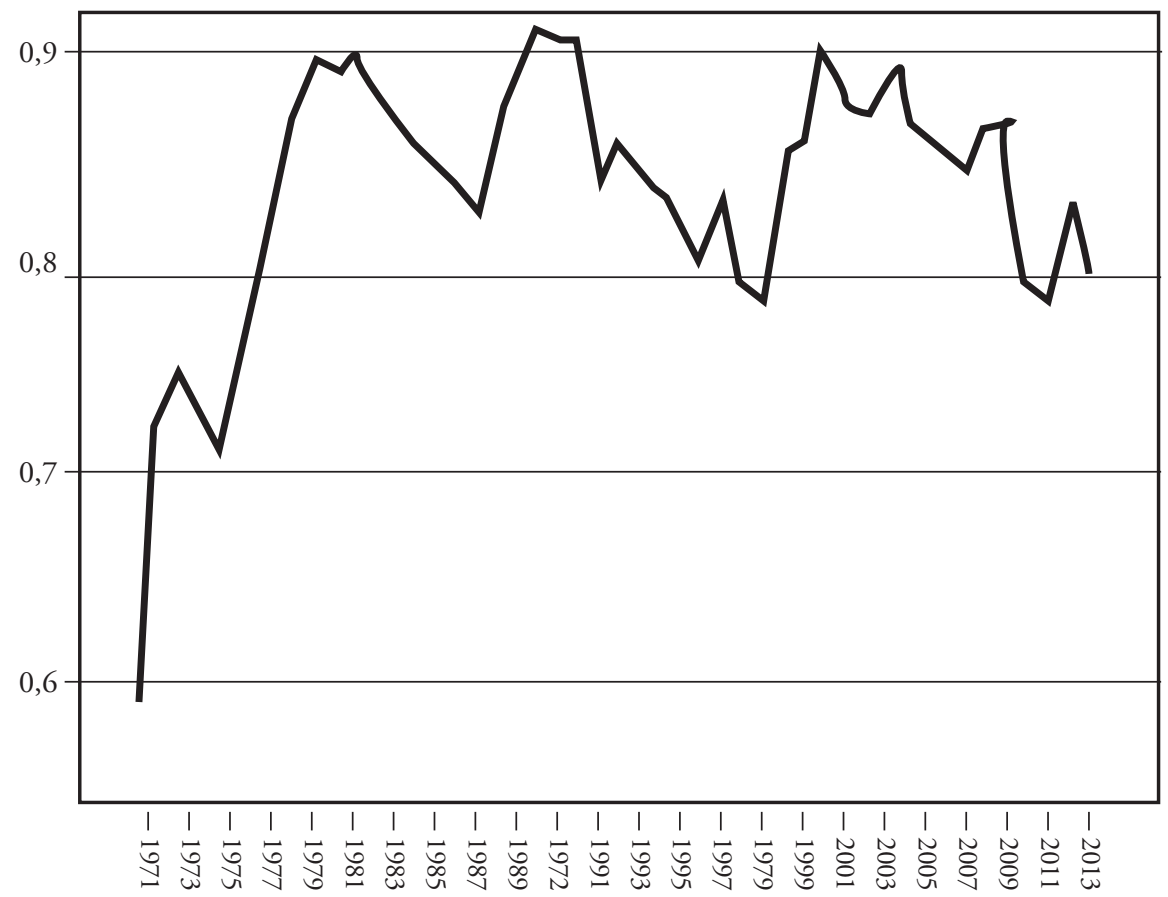

Fonte: Elaborado pelos autores.

mostraram que, sim, os estreitos laços comerciais entre China e África tiveram impacto significativo na convergência em temas de política externa.

Uma agenda de pesquisa que busque capturar as nuances da aproximação sino-africana faz-se necessária na medida em que essas relações têm se tornado cada vez mais complexas. Para além de uma afinidade política e diplomática com fortes raízes históricas, China e África se encontram em um contexto completamente diferente neste século XXI. A desaceleração da economia chinesa para um "novo normal" e o envio de tropas militares chinesas para operaçóes de paz da ONU no continente africano são dois elementos que podem desempenhar papel fundamental nas relaçóes sino-africanas na contemporaneidade.

Como ficam os investimentos para a África com um desenvolvimento chinês mais voltado para a economia interna? O envio de tropas sob o guarda-chuva onusiano impacta a tradicional política de não-intervenção? Perguntas como essas se tornarão frequentes nos próximos anos e os analistas devem estar atentos. Com este artigo, esperamos ter prestado um esforço inicial no sentido de descortinar possíveis padróes e tendências comportamentais desse importante eixo das relaçóes internacionais contemporâneas.

\section{Referências}

ANSHAN, Li. China and Africa: policy and challenges. China Security, v. 3, n.3 p. 69-93, 2007.

FLORES-MACIAS, Gabriel; KREPS, Sarah. The foreign policy consequences of trade: China's commercial relations with Africa and Latin America, 1992-2006. Journal of Politics, v. 75, n. 02, p. 357-71. 2013.

FORUM ON CHINA-AFRICA COOPERATION. The first ministerial conference of FOCAC. Beijing. Anais... Beijing: FOCAC, 2000a. Disponível em: <http://www.focac.org/eng/ltda/ dyjbzjhy/CI12009/t157577.htm>. Acesso em: 17 mar.2015.

FORUM ON CHINA-AFRICA COOPERATION. Forum on China-África cooperation Beijing action plan (20072009). Beijing. Anais... Beijing: FOCAC, 2006. Disponível em: <http://www.focac.org/eng/ltda/dscbzjhy/DOC32009/ t280369.htm>. Acesso em: 17 mar.2015.

FORUM ON CHINA-AFRICA COOPERATION. Addis Ababa Action Plan (2004-2006). Beijing. Anais... Beijing: FOCAC, 2009a. Disponível em: <http://www.focac.org/eng/ltda/ dejbzjhy/DOC22009/t606801.htm>. Acesso em: 17 mar. 2015. 
FORUM ON CHINA-AFRICA COOPERATION. Beijing declaration of the forum on China-Africa cooperation. Beijing. Anais... Beijing: FOCAC, 2009b. Disponível em: <http:// www.focac.org/eng/ltda/dyjbzjhy/DOC12009/t606796. htm>. Acesso em: 17 mar. 2015.

FORUM ON CHINA-AFRICA COOPERATION. Beijing declaration of the fifth ministerial conference of the forum on China-Africa cooperation. Beijing. Anais... Beijing: FOCAC, 2012a. Disponível em: <http://www.focac.org/eng/ltda/dwjbzjjhys/hywj/t954245.htm> Acesso em: 25 mar. 2015.

FORUM ON CHINA-AFRICA COOPERATION. Declaration of the Beijing Summit Of the Forum on China-Africa Cooperation. Beijing. Anais... Beijing: FOCAC, 2006/2009. Disponível em: <http://www.focac.org/eng/ltda/dscbzjhy/ DOC32009/t606841.htm>. Acesso em: 17 mar. 2015.

FORUM ON CHINA-AFRICA COOPERATION. Declaration of the Johannesburg summit of the forum on China-Africa cooperation. Beijing. Anais... Beijing: FOCAC, 2015a. Disponível em: <http://www.focac.org/eng/ltda/dwjbzjjhys_1/ hywj/t1327960.htm>. Acesso em: 25 mar. 2015.

FORUM ON CHINA-AFRICA COOPERATION. Forum on china-africa cooperation Sharm el Sheikh action plan (2010-2012). Beijing. Anais... Beijing: FOCAC, 2009c. Disponível em: <http://www.focac.org/eng/ltda/dsjbzjhy/hywj/ t626387.htm>. Acesso em: 17 mar. 2015.

FORUM ON CHINA-AFRICA COOPERATION. Four-point proposal of the Chinese side. Beijing. Anais... Beijing: FOCAC, 2004a. Disponível em: <http://www.focac. org/eng/ltda/dejbzjhy/CI22009/t157583.htm> Acesso em: 17 mar. 2015.

FORUM ON CHINA-AFRICA COOPERATION. Major commitments of the chinese side. Beijing. Anais... Beijing: FOCAC, 2004b. Disponível em: <http://www.focac.org/ eng/ltda/dejbzjhy/CI22009/t157585.htm>. Acesso em: 17 mar. 2015.

FORUM ON CHINA-AFRICA COOPERATION. The fifth ministerial conference of the forum on China-Africa cooperation: Beijing Action Plan (2013-2015). Beijing. Anais... Beijing: FOCAC, 2012b. Disponível em: <http://www.focac. org/eng/ltda/dwjbzjjhys/hywj/t954620.htm>. Acesso em: 25 mar. 2015.

FORUM ON CHINA-AFRICA COOPERATION. The Forum on China-Africa Cooperation Johannesburg Action Plan (2016-2018). Beijing. Anais... Beijing: FOCAC, 2015b. Disponível em: <http://www.focac.org/eng/ltda/dwjbzjjhys_1/ hywj/t1327961.htm>. Acesso em: 25 mar. 2015.

FORUM ON CHINA-AFRICA COOPERATION. The Second Ministerial Conference of FOCAC. Addis Ababa. Anais... Addis Ababa: FOCAC, 2003a. Disponível em: <http://www.focac.org/eng/ltda/dejbzjhy/CI22009/t157581. htm>. Acesso em: 17 mar. 2015.
FORUM ON CHINA-AFRICA COOPERATION. Two major agenda items of the conference. Beijing. Anais... Beijing: FOCAC, 2000b. Disponível em: <http://www.focac.org/eng/ ltda/dyjbzjhy/CI12009/t157578.htm>. Acesso em: 17 de março de 2015.

GRIMM, Sven. The Forum on China-Africa Cooperation (FOCAC): political rationale and functioning. South Africa: Policy Briefing. Centre for chinese studies, , May, 2012.

VADELL, Javier Alberto; LOPES, Bárbara Ferreira; NASCIMENTO, Daniele Cardoso do. FOCAC: estratégia econômica e política de cooperação Sul-Sul Sino-Africana. Carta Internacional, v.8, n. 2, p. 81-99, jul-dez. 2013.

RODRIK, Dani. Dossiê China: abrindo espaço para a China na economia mundial. Novos Estudos, CEBRAP, n. 89, p. 59-68, mar. 2011.

MEDEIROS, Carlos Aguiar de. O ciclo recente de crescimento chinês e seus desafios. Observatório da economia global. Textos Avulsos, n. 3, junho, 2010.

MENDES, Carmem Amado. Política externa chinesa: um jogo em vários tabuleiros. Revista de Estudos Chineses, v. 27, p. 231-42, 2008.

MENEZES, Gustavo Rocha de. As novas relaçóes sino-africanas: desenvolvimento e implicaçôes para o Brasil. Brasília: FUNAG, 2013.

MITCHELL, Derek; McGIFFERT, Carola. Expanding the "Strategic Periphery": a history of Chinas's interaction with developing world. In: EISENMAN, J.; HEGINBOTHAM, E.; MITCHELL, D (Ed.). China and the developing world: Beijing's strategy for the twenty-first century. New York: M.E. Sharpe, 2007.

PALLANT, Julie. SPSS Survival Manual. [S. 1.]: Open University Press, 2007.

WENPING, He. The balancing act of China's Africa policy. China Security, v. 3, n. 3, p. 23-40, Summer 2007.

SUN, Yun. Africa in China's foreign policy. John L. Thornton China Center and Africa Growth Initiative, 2014. 32 p.

VOETEN, Erik. Data and analyses of voting in the UN general assembly. In: REINALDA, Bob (Ed.). Routledge handbook of international organization. London: Routledge, 2013. Disponível em: <SSRN: http://ssrn.com/abstract=2111149>. Acesso em: 28 dez. 2015. 